A WHITE PAPER

\title{
The PARThenogenerator: Energy out of THIN AIR
}

\author{
Teddy Manning ${ }^{1} \&$ Max Gotts ${ }^{2,3 凶}$ \\ ${ }^{1}$ San Domenico, San Anselmo, California 94960, USA \\ 2 Nueva School, San Mateo, California 94403, USA \\ ${ }^{3}$ Lost Years Institute, Mill Valley, California 94941, USA \\ $\bowtie$ mg@lostyearsinstitute.org
}

\begin{abstract}
We describe a novel machine that uses the greater-than-100\% efficiency of air/ground-source heat pumps to recursively generate electricity via steam-powered generators, taking thermal energy from the ambient environment to convert into electrical power. The invention of a machines that generate clean power at low costs will be fundamental to the future of electricity. We estimate efficiency and calculate minimum efficiencies for unknown parts to consider the applicability of this machine to the real world.
\end{abstract}

Keywords electrical generator; steam-power; air/ground-source heat pump; ambient temperature; parthenogenerator

\section{INTRODUCTION}

Our modern society runs on electricity. The majority of our energy sources used to generate electricity threaten the survival of human society by increasing atmospheric and oceanic levels of carbon, disturbing the global climate (Hill 1979, Hegerl 2005, Myles et al. 2019). Many power sources have been considered and employed to some extent to transition global power consumption away from coal, methane, and other power sources that produce environmentally harmful waste gasses.

Solar power has seen a rise in use as the cost per kilowatt has fallen (cf. Reichelstein \& Yorston 2013), but solar can only work when the sun shines. Wind power is similarly inconstant, and most other power sources such as hydroelectric or geothermal cannot sustain grid consumption (e.g. Barbier 2002). Nuclear power is the only non-carbonemitting technology that can be used at all times to match grid demand with significant power output, but it is expensive and there are fears about its safety. The grid, although supplemented by renew- able energy, still relies on coal and methane powered electric generation for their ability to run continually. Any replacement power source would have to similarly be able to run at any time with sufficient power output.

In this brief white paper we describe a machine that generates electricity using two common devices (the steam engine and the air/ground-source heat pump), to extract energy from the environment.

Air/ground-source heat pumps are notoriously efficient, with measured coefficients of performance (COP, Eq. 1 with numerator = heat, denominator $=$ electric power) consistently in the range of $200-400 \%$ (Wood et al. 2009, Wu 2009, cf. Gurin 2008, Shaw 1999).

$$
\mathrm{COP}=\frac{\text { Energetic output }}{\text { Energetic input }}
$$

Heat pumps function not by creating heat but by extracting it from another source through application of Gay-Lussac's law, enabling a COP $>100 \%$ 
(e.g. Crosland 1961).

We now turn to steam-powered electrical generation (e.g. Smith 2005, Bloomfield 1976, Yannone \& Reuther 1978). Kaviri et al. (2013) finds a net plant efficiency of $49 \%$, and GE reports that they have achieved $63 \%$ efficiency (in combined cycle power plants).

This white paper aims to combine these devices to produce a hypothetical machine (called the parthenogenerator; hereafter, PTG) that has net $\mathrm{COP}>100 \%$ by turning ambient temperature into electrical power.

\section{Formulated DESign}

The PTG in its most basic form would consist of an air compressor and a steam turbine, with the necessary immobile structures to contain the pressurized air and steam. The compressor would continuously pressurize the air and in doing so multiply its temperature. Heat would then conduct through the walls of the containment vessel into the water and steam. The air would then be released out a valve back into the atmosphere, and upon returning to the lower pressure would be frigid.

The steam containing the heat energy from the air would go through a process identical to that which coal, nuclear, and natural gas power plants use, with some of the resulting electrical power going to power the air compressor. Surplus energy would be exported.

For grid-scale purpose built facilities a turbine could be used to compress the air. At the air outlet another turbine could generate energy, all of which could be transmitted back to the pressurizing turbine to mitigate the energy need. The turbine for the purpose of generating electrical power could also port the remaining needed energy to the pressurizing turbine mechanically, erasing the need for an electrical motor to power the pressurizing turbine and the inefficiencies that arise from converting kinetic energy to electric and back again.

This system bankrupts its environment of thermal energy, and so utilizing the waste heat from industrial processes would create a symbiotic relationship. Only at very large scale would worries about thermal depletion of the environment be a concern as air intakes could be placed far from the outlet, and there could be many of each for one system. If necessary heat could be taken from bodies of water or the ground. Structures to trap heat from the sun such as a greenhouse could increase the efficiency of the PTG by slightly preheating the air.

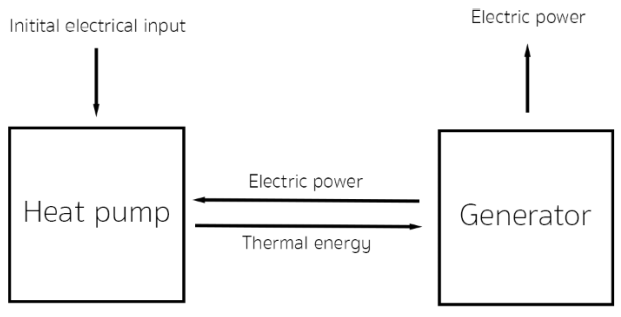

FIG. 1 Diagram of exergy

\section{HYPOTHETICAL EFFICIENCY}

Consider a system as described simply in FIG. 1. Let $\varepsilon$ represent the efficiency of any given part, and have $\varepsilon_{\mathrm{P}}$ represent the heat pump, and $\varepsilon_{\mathrm{G}}$ repre- sent the generator. There is a measure of efficiency $\varepsilon_{\mathrm{G} \rightarrow \mathrm{P}}$ for the transmission of electric power from the generator to the heat pump, and an efficiency $\varepsilon_{\mathrm{P} \rightarrow \mathrm{G}}$ for the transmission of thermal energy follow- 
ing the opposite path. We choose a fraction $\chi$ of the generator's power to store in a battery (or export to a grid). Consider now an initial input of electrical energy $E_{0}$ (measured in joules) and without loss of generality assume $100 \%$ efficiency of the input of this electricity to the heat pump (i.e. $E_{0}=\varepsilon_{i} E_{i}$ for some entry energy $E_{i}$ and efficiency $\varepsilon_{i}$ ).

Then we have the internal energy after $K$ cycles:

$$
E(K)=\left(E_{0} \varepsilon_{\mathrm{P}} \varepsilon_{\mathrm{P} \rightarrow \mathrm{G}} \varepsilon_{\mathrm{G}} \chi \varepsilon_{\mathrm{G} \rightarrow \mathrm{P}}\right)^{K}
$$

And the exergy

$$
\Xi(K)=\left(E_{0} \varepsilon_{\mathrm{P}} \varepsilon_{\mathrm{P} \rightarrow \mathrm{G}} \varepsilon_{\mathrm{G}}(1-\chi) \varepsilon_{\mathrm{G} \rightarrow \mathrm{P}}\right)^{K}
$$

Thus the produced energy

$$
B(K)=\sum_{j=1}^{K}\left(E_{0} \varepsilon_{\mathrm{P}} \varepsilon_{\mathrm{P} \rightarrow \mathrm{G}} \varepsilon_{\mathrm{G}}(1-\chi) \varepsilon_{\mathrm{G} \rightarrow \mathrm{P}}\right)^{j}
$$

At cycle $K$, the net engine efficiency is $\Xi(K) / E_{0} \propto E_{0}^{K-1}$. Assuming $\chi=0.5, \varepsilon_{\mathrm{P}}=4$, $\varepsilon_{\mathrm{G}}=0.63$, we derive that $\varepsilon_{\mathrm{G} \rightarrow \mathrm{P}} \varepsilon_{\mathrm{P} \rightarrow \mathrm{G}}=0.79^{K}$ if we want a COP of $100 \%$. If the product is any greater then the net generator efficiency is greater than $100 \%$, allowing us to turn ambient temperature into electricity. As an example, for $K=10$, this value must be above $0.99 \%$, an easy ask.

Clearly, at some point the machine will vent the excess energy. In this case we simply yield a greater exergy $\Xi(K)$ to keep $E(K)=E(K+1)$, essentially implementing an $E(K)$-dependent $\chi$. Once the power generation facility reaches its capacity all further energy will be exported.

Assume that the product of the unknown inefficiencies is consistently $80 \%$ (a reasonable estimate), and define $\chi(K)=0.9^{K}$. Then let $E_{0}=1$ joule and see that $B(10)=\sum_{j=1}^{10}\left(1.26 \cdot 0.9^{j} \cdot 0.8\right)^{j} \approx$ 2.27 joules. Now let $E_{0}=10$ joules so that $B(10) \approx 718,589$ joules. Finally, $E_{0}=100$ yields $B(100) \approx 3.1 \times 10^{15}$ joules.

\section{Conclusion}

The capacity to generate electricity recursively via greater-than-100\% efficiency may become vital in the future as more companies and cities move towards renewable energy sources, or may prove cost efficient enough to out-compete methane and coal fired power plants. Whilst research has yet to be done on a physical implementation of these designs, the prospects are bright. The PTG is scale-able and would function consistently across differing conditions and locations. The PTG could be used as a mainstay for grid production, as an off-the-grid small scale generator, or as an energy source for ships that could preclude the need to refuel.

This system is limited in that without parts of a certain efficiency it will not be energy positive. Presently the issue comes from the low efficiency of small scale heat to electricity converters such as small steam turbines, but future development should yield higher efficiency designs and increased performance in other domains can compensate for the low performance of turbines.

\section{BIBLIOGRAPHY}

Barbier, E. (2002). Geothermal energy technology and current status: an overview. Renewable and Sustainable Energy Reviews, 6(1-2), 3-65. doi:10.1016/s1364-0321(02)00002-3

Bloomfield D. P. (1976) Pressurized fuel cell power plant with steam powered compressor. US3982962A

Crosland, M. P. (1961). The origins of Gay-Lussac's law of combining volumes of gases. Annals of Science, 17(1), 1-26. doi:10.1080/00033796100202521

Gurin, M. H. (2008) High efficiency absorption heat pump and methods of use. US7313926B2.

Hegerl, G. C. (2005). OCEAN SCIENCE: Warming the World's Oceans. Science, 309 (5732), 254-255. doi:10.1126/science.1114456

Hill, L. E. (1979, October 16). Controlling Atmospheric CO2. Exxon Engineering Petroleum Department. Retrieved from http: //insideclimatenews.org/sites/default/ files/documents/CO2\%20and\%20Fuel\%20Use $\%$ 20Projections.pdf

Kaviri, A. G., Jaafar, M. N. M., Lazim, T. M., \& Barzegaravval, H. (2013). Exergoenvironmental optimization of Heat Recov- 
ery Steam Generators in combined cycle power plant through energy and exergy analysis. Energy Conversion and Management, 67, 27-33. doi:10.1016/j.enconman.2012.10.017

Myles A., Babiker M., Chen Y., de Coninck H. et al. (2019). IPCC Special Report: Summary for Policymakers. Retrieved from https: //www.ipcc.ch/site/assets/uploads/sites/ 2/2019/05/SR15_SPM_version_report_LR.pdf Reichelstein, S., \& Yorston, M. (2013). The prospects for cost competitive solar PV power. Energy Policy, 55, 117-127. doi:10.1016/j.enpol.2012.11.003

Shaw, D. N. (1999) Boosted air source heat pump. US5927088A.

Smith, E. J (2005) Electro-water reactor steam powered electric generator system. US6951105B1

Wood, C. J., Liu, H., \& Riffat, S. B. (2009). Use of energy piles in a residential building, and effects on ground temperature and heat pump efficiency. Géotechnique, 59(3), 287-290. doi:10.1680/geot.2009.59.3.287

GE Power (2018). World's Most Efficient Combined-Cycle Power Plant https://www.ge . com/power/about/insights/articles/2018/ 03/nishi-nagoya-efficiency-record

Wu, R. (2009) Energy Efficiency Technologies Air Source Heat Pump vs. Ground Source Heat Pump, Journal of Sustainable Development 2(2) https://pdfs.semanticscholar.org/f65c/ a56837bdb2d4a4d1a22433a3fcea279ccb3b.pdf

Yannone, R. A. \& Reuther J. F. (1978) Black start system for large steam powered electric generation plants. US4103178A

\section{Author Contributions}

TM formulated the concept and co-authored the paper. MG co-authored the paper with a focus on the mathematics. 